\title{
Quantitative Literacy for the Future Flourishing of our Students: A Guiding Aim for Mathematics Education
}

Samuel L. Tunstall

Michigan State University, stunstal@trinity.edu

Follow this and additional works at: https://digitalcommons.usf.edu/numeracy

Part of the Curriculum and Instruction Commons, Metaphysics Commons, and the Science and Mathematics Education Commons

\section{Recommended Citation}

Tunstall, Samuel L.. "Quantitative Literacy for the Future Flourishing of our Students: A Guiding Aim for Mathematics Education." Numeracy 10, Iss. 1 (2017): Article 7. DOI: http://dx.doi.org/10.5038/

1936-4660.10.1.7 


\title{
Quantitative Literacy for the Future Flourishing of our Students: A Guiding Aim for Mathematics Education
}

\begin{abstract}
In this essay, I examine the extent to which mathematics education and education for quantitative literacy support students' present and future flourishing, a concept that entails realizing objective goods in a life lived from the inside. This perspective requires disentangling philosophical assumptions about the aims of mathematics education, which-in the context of flourishing-I take to be a hybrid of those that have informed curricular discussions over the past two centuries. In the process, I problematize ("make strange") many of the common reasons given for students learning mathematics, including: learning it for one's career, for one's logical reasoning skills, or for its own sake. My conclusion is that, through the end of compulsory schooling, all students should take coursework that fosters quantitative literacy, or the ability and disposition to use, interpret, and criticize numbers as they manifest in daily life. In addition, in the same environment, traditional mathematics should be included and compulsory up to grade eight, but afterward required only insofar as it is necessary for fulfilling one's goals. I pursue this line of argument with full cognizance of sociopolitical elements of mathematics education and other challenges in implementation, noting that appealing to consequences-while fine as a justification for avoiding change in the short-term-is not a tenable justification for doing so in the long-term. I challenge readers to reflect on our ability to empower students for future flourishing, and to consider the role that mathematics has in doing so.
\end{abstract}

\section{Keywords}

quantitative literacy, curriculum, philosophy

\section{Creative Commons License}

\section{c) (i) (8)}

This work is licensed under a Creative Commons Attribution-Noncommercial 4.0 License

\section{Cover Page Footnote}

Samuel Luke Tunstall is a graduate student in mathematics education and University Distinguished Fellow at Michigan State University. He has taught mathematics at multiple levels and is interested in the sociology of mathematics education, as well as curricula that promote quantitative literacy. 


\section{Introduction}

Chapter 4 of On Education by University of Wisconsin philosopher Harry Brighouse is titled "Education for a Flourishing Life." In it, he asks (Brighouse 2006, 64), "What can and should the education system do ... in pursuit of its obligation to prepare (students) to live flourishing lives?” In this perspective paper, I examine how mathematics education-and education for quantitative literacy - currently contribute to the goal of educating students for a flourishing life. Given the focus of flourishing on the individual, it need not be the only quality educators support; indeed, democratic citizenship matters too (Dewey 1920; Steen 2001), as do other things. That being said, my focus here is on flourishing, which-as we will soon see-is a broad notion that should be of importance to all educators. After explaining the construct and situating it within the various ideologies at play in U.S. mathematics education, I then transition from is to ought, recommending that if flourishing is to be a guiding aim of our public education system, then we should have less required mathematics after grade eight, and a heavier emphasis on quantitative literacy in all areas of schooling-primary, secondary, and post-secondary. My analysis is intended to prompt reflection and even cause episodes of cognitive dissonance among those involved in teaching mathematics - which I view as a good thing, because implementation of the recommendations would be a challenge, requiring work on the part of most educators in a number of disciplines.

My goal here is not to stir up controversy but rather encourage meaningful discussion about why we, as individuals involved in teaching mathematics or related subjects, do what we do. Given the practical issues inherent in implementing reform-coupled with the fact that my views are certainly debatable-I, of course, recognize that change cannot and should not happen immediately. With that said, however, I do believe the existence of barriers to change is not a sufficient reason to avoid dialogue.

In addition to the aforementioned goals, another aim is to provide a base from which advocates for quantitative literacy might argue for less traditional mathematics in secondary and post-secondary curricula. This position will build upon and strengthen our current position - that of quantitative literacy for democracy (Steen 2001)—while simultaneously leaving room for further exploration into the precise connections between quantitative literacy and flourishing. 


\section{Stepping Back from the Familiar}

I begin the task set out above by making the familiar strange (Mills 1959), stepping back from the dense forest of mathematics education to situate our efforts within a historical perspective. As Stanic $(1986,190)$ points out, "Without curriculum history, we have tunnel vision about current problems; we see them in a restricted framework." That is, as he goes on to explain, without an understanding of where mathematics teaching has come from, those in mathematics education who lament it may only exacerbate the problems that they aim to fix. It is interesting to note here that we see Stanic's concern about awareness playing out today. The Common Core State Standards for Mathematics (CCSSM) - the newly dominant and controversial standards used for $\mathrm{K}-12$ mathematics education-appear to have been created with little historical understanding. Indeed, in spite of the fact that we have gone through more than a century of similar reform efforts (Stanic 1986), the preamble of the CCSSM notes:

For over a decade, research studies of mathematics education in high-performing countries have pointed to the conclusion that the mathematics curriculum in the United States must become substantially more focused and coherent in order to improve mathematics achievement in this country. To deliver on the promise of common standards, the standards must address the problem of a curriculum that is "a mile wide and an inch deep.” These Standards are a substantial answer to that challenge. (National Governors Association Center for Best Practices \& Council of Chief State School Officers 2010, 3).

Notably, there is no mention here that mathematics educators waged battles for curricular coherence at the turn of the twentieth century (Stanic 1986), and they have engaged in similar efforts ever since. Of course, a full analysis of the standards themselves is outside the scope of the paper. ${ }^{1}$ The main point to take from this reference is that, given the various issues discussed over the years in mathematics education at both the compulsory and post-compulsory levels (e.g., Steen 2001; Schoenfeld 2004), it is intuitively obvious that historical awareness is key for engaging in meaningful reform discussions (Stanic 1986). So, what do we see happening in $\mathrm{K}-12$ mathematics education now, and how does it relate to what came before it?

Today, a typical child going through the U.S. public education system will take ten to twelve years of mathematics courses. At the secondary level, this coursework often includes topics from Algebra 1, Geometry, and Algebra 2 (or some permutation of the topics therein). What other disciplines have the privilege of so much student time? Aside from English-sometimes referred to as language arts—no other discipline permeates a students' schooling experience as much as

\footnotetext{
${ }^{1}$ See Madison (2015) for a look at the standards through the lens of quantitative literacy.
} 
mathematics does. Though most of us now assume that mathematics is simply a part of the routine of being in school (Dowling 1998), it is important to note that continuous mathematics instruction of this manner and content is not an immutable phenomenon.

From a historical perspective, the arrangement of enrolling students in nearly a decade of mathematics courses is rather young, given that universities such as Yale and Princeton did not require knowledge of arithmetic for admission until the mid-eighteenth century (Cohen 2002). Even when arithmetic was taught or reviewed at universities, the elite students who took such courses viewed the subject as garish and unfit for anyone but merchants. Arithmetic was taught as a memory-based subject to the few older students who were destined for a commercial life-it had no place in the schools and colleges of early America (Cohen 2002). Such views of arithmetic (and mathematics in general) remained relatively stable until decades after the American Revolution. In fact, it was not until the mid-nineteenth century that students began to enroll in public schools in large numbers (Stanic 1986), at which time, due to an increase in commerce and a desire for a rational citizenry (Cohen 2002), the traditional mathematics curriculum of algebra, geometry, and trigonometry made its way to the ranks of secondary schools. This time was an important period in which mathematics began to be viewed as a proxy for teaching logic and rationality-key subjects for any informed citizenry of a republic. Since the mid-nineteenth century, we have seen waves of mathematics education reform from a number of individuals and parties, each of whom had their own views of how and why mathematics should be taught (Stanic 1986). Notably, however, each reform has maintained roughly the same sequence of topics as is standard in U.S. secondary mathematics education today.

Despite the fact that students currently spend a decade enrolled in mathematics courses, many today consistently bemoan the state of mathematics education across the globe (e.g., Kilpatrick et al. 2001). It seems that most would agree that the current curriculum is not meeting its aims. For this reason, with historical awareness in hand, I believe we should take a further step back to examine our assumptions about the aims of mathematics education and of education at large. In focusing on its engineering in schools (i.e., the content of mathematics and how it is taught), we tend to obscure its ends (Postman 1996). Even as policy initiatives such as the Common Core declare that standards should be designed so students succeed in the workforce and in life (National Governors Association Center for Best Practices \& Council of Chief State School Officers 2010), it remains murky as to how exactly such standards-and mathematics education as a whole-might support those goals. As Stanic (1986, 190) notes, "We cannot assume that our forebears were any less confused than we are," and 
hence it is unwise to accept the status quo without some sort of critical examination.

With these thoughts in mind, I next examine mathematics teaching with a top-down approach, first identifying flourishing as a guiding aim for education and then discussing how mathematics teaching might play a role in supporting that aim. This tack might generate insights overlooked by the more common bottom-up approach which implicitly assumes a role of mathematics in education and then works back to what the aims of education might include.

\section{A Guiding Aim}

The guiding aim I adopt is that the U.S. public school curriculum should foster students' present and future flourishing (Brighouse 2006), a concept-in the context of education-similar to Hilton's (1984) notion of a successful life. The idea of human flourishing is certainly not new. Philosophers have consistently discussed notions of the good life since Aristotle's treatment of Eudaimonia (a word roughly translating to flourishing) (Reeve 2014), and today we see various elements of flourishing in movements in positive psychology (Seligman 2011) and related theories of economic development and social justice (Nussbaum and Sen 1999). For this paper, I focus on the approach and operationalization of Brighouse's (2006), as his lens specifically includes the context of education.

For Brighouse, flourishing is a rather individualistic construct-one that does not explicitly address fostering community or democracy. However, as I will discuss later, it need not be the only goal for education. According to Brighouse (2006, 16), flourishing consists of realizing objectively valuable goods in a life that is lived from the inside. He defines objectively valuable goods to be those that make life worthwhile and are worth pursuing for their own sake. There is some disagreement (as there should be) about the precise list of objective goods, but a common list includes things like enjoyment, mutual friendship and intimacy, accomplishment, personal autonomy, and to some extent, material goods (Ferkany 2012; Rice 2013). The goods Brighouse $(2006,15)$ has in mind are achieved in activities like "raising children, mastering difficult and complex skills, giving enjoyment to others and enjoying their company, studying great literature, [and] devising great comic routines" and not in activities like hoarding money or things. Such goods are realizable by people in a wide diversity of lifestyles, religious and non-religious, professionally ambitious or not professionally ambitious, heterosexual or LGBTQ, and so on. However, attaining objectively valuable goods is only necessary and not sufficient for a flourishing life. For example, consider a woman who stays home to raise children. While establishing an intimate relationship with children in a stay-at-home context may be an objective good, this lifestyle may be entirely at odds with her internal aspirations in 
professional life. A person can flourish within a way of life only if she can also identify with it or "live it from the inside." To that extent, flourishing also requires a capacity to find a way of life that matches a personal point of view, particularly for skills associated with personal autonomy, or "skills of rational reflection and comparison” (Brighouse 2006, 18).

Based on these notions, one can flourish through a spectrum of activities, ranging from having a career, to spending time with friends and enjoying hobbies or other interests. Flourishing is clearly an open-ended idea, and hence narrow paternalistic oversight on the part of public schools is not necessary for flourishing - quite the contrary. With that said, the construct may not appeal to all, to which Brighouse $(2006,45)$ notes:

Any theory of flourishing is...inevitably controversial: some readers will disagree with me that happiness and flourishing are not the same thing, while others will think of flourishing in a variety of religious terms, and others still in terms of the exercise of particular capacities or virtues.

Hence, flourishing and its operationalization are subject to legitimate critiques; however, this vulnerability is not cause for avoiding an aim altogether. Flourishing is meant to broadly encompass a variety of notions we know help individuals thrive. Indeed, it is hardly a novel idea for mathematics education, as it embraces many of the ideologies that pervade our current discourses (Tunstall 2016) of why we teach the subject. Moreover, mathematics's support of flourishing can be understood in the context of each of the major ideological camps within the history of mathematics education described in Stanic (1986) and Ernest (2002): humanists, developmentalists, social efficiency (or utilitarian) educators, and social meliorists. It aligns with humanist goals insofar as it encourages one to pursue a worthwhile (or liberal) education, and also with developmentalist goals as it necessarily accounts for one's own desires-not just those viewed by others as "intrinsically worthwhile" (Hilton 1984, 2). It aligns with social efficiency goals because it encourages the pursuit of autonomously chosen interests relevant to future lives and careers while at the same time it makes no assumption about pre-defined roles for students within society. Finally, flourishing aligns with social meliorist goals, as it aims for the flourishing of all, paying particular attention to the realities of systemic marginalization. I discuss the latter goal in some depth later.

Notably, an ideological aim absent from above is democratic citizenship, the often-articulated ideal of many in the quantitative literacy community (see Steen 2001). Fostering flourishing - a rather individualistic construct - does not directly foster good citizenship, and hence here we find a need to augment this aim for education with one for good citizenship, too. As Brighouse $(2006,63)$ notes: "Both academic and political discussions of education tend to take it for granted that one of the central aims of schooling is to produce good citizens." It is unwise 
to believe that one construct could encompass everything schools should aim for in education, and hence we find a necessary partnership between education for flourishing and education for quantitative literacy, the latter of which aims for participation in democracy (among other things). With that said, the purpose of this paper is to highlight how mathematics teaching, as well as teaching for quantitative literacy, can foster flourishing. Hence, though I will continue to focus on flourishing, the reader should remain cognizant that it need not be the only aim for schooling.

\section{Mathematics for Flourishing}

The major goal of this paper is to consider the extent to which teaching for mathematics and teaching for quantitative literacy can promote flourishing. To that end, I begin by discussing how we might understand traditional mathematics teaching - that which focuses on mathematical literacy - as fostering the aim of flourishing.

As noted above, current U.S. mathematics curricula tend to foster mathematical literacy, including algebraic manipulation and computational dexterity (Madison 2003); in many ways, mathematical literacy is encompassed by the notion of symbol sense (Arcavi 2005). Large-scale attempts to measure mathematical achievement-such as the Programme for International Student Assessment—primarily examine students' mathematical literacy (Wilkins 2010). In addition to its intrinsic rewards, common reasons for supporting mathematical literacy include its purported ability to: (1) open access to jobs and (2) build capacity for critical thinking, and so enable intelligent decisions as citizens, consumers, and as persons. Below I discuss each of these.

Having a career certainly may contribute to a flourishing life, as a career is an objective good that provides income security and-assuming the person enjoys the work-intrinsic rewards. A number of careers make use of the mathematics learned in secondary and post-secondary schooling (e.g., engineering), and students who want to engage in such work should have access to the coursework necessary for doing so. However, not all careers require mathematics skill. Instead, for many careers success in coursework is simply exchanged for status and pay (i.e., objective goods) (Labaree 1997, 2014; Williams 2012). This is especially true in learning mathematics, where competency in the discipline often permits one to enter university (through one's SAT scores), exit university (through general education requirements), and even obtain a job (through one's GPA), completing significant, status-earning tasks that-in and of themselveshave no significant relation to the mathematics itself. These examples typify exchange value. Research readily confirms this advantage, as mathematical ability (defined through grades or test scores) is connected to both wage increases and 
likelihood of fulltime employment (Eide and Grogger 1995; Levy et al. 1995; Rivera-Batiz 1992). In response to this, some might note this advantage is simply a matter of economics; the laws of supply and demand dictate these patterns, not us - the problem is structural, not related to the mathematics itself (Williams 2012). This is a fair point; however, it does not discount that for the majority of careers, whether high-paying or not, higher-level mathematics has little use value. Among other issues, exchanging mathematics credentials for status unrelated to the mathematics itself disadvantages students who have not had the privileges that foster mathematical achievement.

Even if we reject the idea of mathematics as mere exchange good, we still must face challenging questions about the traditional curriculum. For example, some argue that properly taught mathematics fosters problem-solving and logical reasoning skills - competencies that transcend the discipline itself. That is, even if mathematics has little direct use value students can benefit from learning mathematics in ways that legitimately make them better workers and citizens, among other things (Cohen 2002, Gibson 1986; National Council of Teachers of Mathematics 2000, Schoenfeld 2016, Whitney 1987). Admittedly, mathematics and logic are inherently intertwined (Gibson 1986; Siegel 1988), and mathematics - when taught properly_certainly can foster one's problem-solving ability. Still, considering the everyday importance of reasoning and problemsolving, and the lesser need for mathematical content knowledge for most people (Gibson 1986), we must ask why we use the largely unneeded subject as a proxy for the needed one (assuming we desire to empower students with reason and problem-solving skills) (Gibson 1986). At the very least we must consider alternatives. For example, proponents of quantitative literacy argue that teaching for quantitative literacy also cultivates skills in critical reasoning (Hillyard 2012).

Others avoid the question of mathematics's use value altogether, arguing that it is a beautiful discipline - an art to be shared with the world, and an essential component of any liberal education (Mumford 2006; Woodhouse 2012). There is no need to justify the subject's utility; the ends and means are one in the same. Texts supporting this view of mathematics are readily available, including The Heart of Mathematics (Burger and Starbird 2012) and Mathematics: A Practical Odyssey (Johnson and Mowry 2015), among a host of others. At issue here is the underlying humanist assumption that students need a liberal education. Brighouse (2006) notes that paternalism is necessary to some extent among educators to support flourishing, and naturally this would involve deciding that some subjects (e.g., writing, history) are more important than others (e.g., Swahili). Hence, there is some merit in mandating a liberal education for all students. Still, the humanist tendency to continue marching through mathematics courses in public schooling (after developing quantitative literacy skills)—albeit well-intended-runs counter to the notion of flourishing if it clashes with students' interests. Indeed, the second 
component of Brighouse's (2006) framework, living a life aligned with inner desires, dictates that the individual be able to pursue personal passions. On an extreme level, this means that an Amish child be able to choose a different lifestyle as she grows older (Brighouse 2006); more mundane, but applicable here, is that students be able to take coursework in subjects of their choice. Coursework in mathematics is readily offered by most schools, though its equitable accessibility is contentious (Berry 2008). But with or without access to mathematics courses, most students are less likely to be able to focus on courses in subjects such as art, geography, or sociology, among many others, should they desire to do so (Labaree 2014). I leave it to the reader to ponder what might replace four years of mandatory high-school mathematics for students; they might engage in discovering psychology, sociology, human geography, and philosophy, among a host of other disciplines, all of which would aid in directly developing students' reasoning and communication skills-skills many equate as an inherent reason for learning mathematics. (Whitney 1987).

From the above discussion, I have problematized common rationales for teaching mathematics courses in U.S. public schools. In the context of flourishing, it appears that mathematics above arithmetic is unnecessary for most jobs (Rosen et al. 2003), and that we perhaps unwittingly abuse its potential for supporting logical reasoning skills. Most importantly, the subject takes up room in a crowded curriculum that might otherwise be used for subjects of interest to students (Labaree 2014). While absolutely useful for some-be it of intrinsic interest, or necessary for one's career-it is unclear if that means all students should be forced to take courses in the subject in each grade until graduation.

Though I have criticized traditional mathematics teaching, it is still not apparent how education for quantitative literacy ${ }^{2}$ might support flourishing. An easy answer to the question is that we live in a world "awash with numbers," and thus that quantitative literacy is necessary for full participation (Steen 2001, 1). Because flourishing is dependent upon participation in society it depends on quantitative literacy. Indeed, if numbers (in various forms) are as ubiquitous as words, it makes sense that "An innumerate citizen today is as vulnerable as the illiterate peasant of Gutenberg's time (Steen 1997, xv).

But perhaps this is too straight-forward. Notwithstanding all the rhetoric surrounding quantitative literacy over the past decades, its actual necessity remains rather ill-defined (Erickson 2016). This is not to discount the very real connections that have been found, but rather to call attention to the need for more explicit links between quantitative literacy and flourishing. We know quantitative literacy fosters informed decision-making with respect to nutrition (Rothman et

\footnotetext{
${ }^{2}$ By "quantitative literacy" I mean the amalgamation of skills, dispositions, and critical awareness that enables one to participate successfully in situations involving numbers, whether the numbers are visual, written, or spoken. See Karaali et al. 2016 for a discussion of alternative definitions.
} 
al. 2006), medicine (Fagerlin et al. 2007; Lipkus and Peters 2009), risk situations (Jasper et al. 2013), and financial matters (Allgood and Walstad 2013; Nye and Hillyard 2013; de Bassa Scheresberg 2013) (among other things), all of which can support one's attainment of objective goods like leading a healthy and prosperous life. In addition, it is increasingly clear that numeracy skills are necessary as a use good in a wide range of jobs (e.g., administrative assistants, factory workers, nurses, etc.) (Rosen et al. 2003); that is, numeracy brings about objective goods while allowing one to pursue career interests. However, more work is needed to flesh out other means by which quantitative literacy might influence flourishing. Indeed, a lingering question is the extent to which elementary mathematical skills are necessary for understanding and reacting to day-to-day issues involving numbers.

\section{Implications}

If taken seriously, the observations above have profound consequences. Teaching for quantitative literacy may be a better curricular choice than traditional mathematics coursework if we aim to support flourishing. Of course, even this perspective acknowledges traditional mathematics's supporting role. I have problematized two common arguments for learning mathematics beyond grade eight, noting that quantitative literacy may be a better route, unless students need or want to learn more mathematics. If this is true, what are we to do? Because it has been argued that the seeds of quantitative literacy are sewn in grades $\mathrm{K}-8$ (Hughes-Hallett 2003), I believe that through grade eight, students (in non-tracked classrooms) should all participate in an engaging, challenging mathematics curriculum that promotes both mathematical literacy and quantitative literacy. This would prepare students for the mathematics they would encounter in higher levels, should they choose to enroll in such, as well as sow the seeds for critical thinking using numbers outside of school. Curricula for the primary grades that support both of these goals in a genuine fashion (i.e., where real-world contexts are not contrived) are difficult to find, though Investigations ${ }^{3}$ is a promising start.

Beyond grade eight, perhaps it should be up to students - not test scores or advisers - to decide whether they desire to take further courses in mathematics, meaning that direct mathematical coursework should be available for all, but not mandatory. At the same time, courses in other disciplines (e.g., biology, English,

\footnotetext{
${ }^{3}$ Investigations in Number, Data, and Space, $3^{\text {rd }}$ edition (2017), a K-5 inquiry-based approach to teaching mathematics, funded by Pearson, TERC, and the National Science Foundation. See investigations.terc.edu and

http://www.pearsonschool.com/index.cfm?locator=PS2s6r\&PMDbSiteId=2781\&PMDbSolutionId $=6724 \&$ PMDbSubSolutionId=\&PMDbCategoryId=806\&PMDbSubCategoryId=25741\&PMDbSu bjectAreaId=\&PMDbProgramId=139441 (accessed Nov. 23, 2016)
} 
sociology) could begin reinforcing the skills and critical reasoning of quantitative literacy as they manifest from within the respective discipline, following a spiraling approach akin to that suggested by Bruner (1977) or Whitehead (1929). This means the envisioned curriculum would be interdisciplinary (Hughes-Hallett 2003; Steele and Kiliç-Bahi 2008), integrating quantitative skills and critical thinking across the disciplines, regardless of whether the student is taking further mathematics courses. For example, though students may develop a basic conception of percentages in primary school, they would revisit the concept often in later grades, discussing concepts like percent change, the distinction between relative and absolute change, or even how the stock market works-meaningful and challenging applications. Mathematics would never leave the curriculum; students simply would not be forced to take it as a standalone course after grade eight. (It must be stressed that the implied curriculum would require substantial revision across many secondary school departments; I am not aware of any existing curricula that integrate quantitative literacy skills across the disciplines.)

If flourishing is our aim, similar revision to post-secondary coursework and graduation standards would need similar revision. College instructors in relevant disciplines (e.g., sociology, geography, communications, etc.) could foster quantitative literacy in the context of authentic problems, and mathematics requirements for graduation might be re-envisioned to promote sophisticated quantitative literacy, unless students had a desire for learning more about mathematics for its own sake. While such a vision would clearly demand substantially new college courses and requirements, examples of cross-cutting curricula at the college levels are more readily identified (Steele and Kiliç-Bahi 2008).

\section{Issues and Rebuttal}

Even readers sympathetic to my reasoning thus far are likely to have good reasons to be wary of these proposals. Here I focus on qualms concerning implementation, not with the reasoning of flourishing itself. First, we must not conflate curriculum with its enactment in the classroom-whether at the $\mathrm{K}-12$ or college level. Fostering quantitative literacy in this interdisciplinary manner is no simple matter, as it would require development efforts from both major curricular voices and textbook publishers and significant work on the part of teachers and college instructors without a heavy mathematics background. Without careful implementation, the skills of quantitative literacy may go untaught in a curriculum where mathematics is not directly allotted time (Brighouse 2006, 53). The envisioned program would also require professional development for mathematics teachers up to grade eight, because as Cranfield $(2012,209)$ notes, a curriculum that fosters quantitative literacy "challenges the beliefs and understandings of 
mathematics teachers who were trained under very different assumptions regarding the teaching of mathematics." That is, one's training through traditional mathematics coursework is not sufficient for teaching that fosters quantitative literacy. While these concerns would demand attention, we should not use them as excuses to maintain thoughtlessly a status quo that most argue is failing students.

Second, the curriculum discussed in the previous section could exacerbate social inequities. Indeed, given the inequities typically associated with tracking, it is logical that one might view this proposal with caution (Oakes 1982). With our nation's recent push to make STEM careers available to all students-especially those in historically marginalized groups-the proposal might appear a step backward. We cannot ignore issues of access to higher-level mathematics, particularly for historically marginalized groups. Movement groups for equity in education, such as the The Algebra Project led by Robert Moses (Silva et al. 1990), would likely push back against any system for fear that it might disproportionately disadvantage minority groups. I concede that, given the current stratification of U.S. society, this would perhaps be an unavoidable consequence of any curriculum in which students have autonomy and choice. I would argue, however, that this reflects less on the proposed curriculum than on the earlierdiscussed notion of exchanging mathematics for status (Labaree 1997 and 2014). On the one hand, it is a curricular issue if marginalized groups are underrepresented in STEM fields because students' curricular choices-on the aggregate-yield fewer opportunities for participation; on the other hand, it is a larger societal issue, beyond the curriculum, if we allow students to exchange credentials in mathematics for status and pay that has little to do with the mathematics itself. Indeed, there is nothing inherent about my proposed curriculum that disadvantages certain groups; it is the system in which we live that creates the problem. I would argue that we should not facilitate the inequality-exacerbating exchange value system through the current mathematics sequence; doing so out of a push for equity or unfounded fears only perpetuates the problem. In fact, a shift from mathematics literacy to quantitative literacy may healthfully undermine the system of exchange value because quantitative literacy has actual use value in far more endeavors

\section{Conclusion}

Many have long suggested that in order to improve mathematics education, we need to-among other things-disrupt traditional ways of teaching (Gadanidis 2012), make the content more coherent and connected with reality (Stanic 1986; Woodhouse 2012), and make available the benefits of mathematical knowledge to everyone (Apple 1992). These are admirable aims; however, in this paper, I have 
argued that to a large extent, we may need to go further if we are to disrupt the root of the problem: that, perhaps after a certain point, mathematics is simply unnecessary for most students to flourish. As Pais $(2013,5)$ eloquently notes, "If the purpose is the high ideals of peace, democracy, social justice and equality, the route via mathematical thinking, in which we currently invest so much, is a dead end."

I recognize the radical nature of my proposal and the inherent complexities and issues embedded within its implementation. This analysis is meant primarily to spark dialogue, not ruffle feathers. My perspective is fallible, but nonetheless can hopefully provide a starting point for us-as a community - to continue considering the philosophical aims of what we do that go beyond the notion of championing democracy. Given the widespread agreement that the status quo is failing students, it seems untenable to advocate for more of the same. As an alternative, I have attempted to model how awareness and articulation of the aims of education can lead us into larger conversations about potential revisions to the mathematics curriculum. I encourage educators and policy-makers to reflect on our complicity in the matter, as, albeit we are often well-intended, by allowing the current quantity and nature of mathematics content in schools to remain constant, we ignore a large component of the problems we aim to fix.

\section{References}

Allgood, Sam and William Walstad. 2013. "Financial Literacy and Credit Card Behaviors: A Cross-Sectional Analysis by Age.” Numeracy 6 (2): Article 3.

Apple, Michael W. 1992. "Do the Standards Go Far Enough? Power, Policy, and Practice in Mathematics Education.” Journal for Research in Mathematics Education 23 (5): 412-431. https://doi.org/10.2307/749562.

Arcavi, Abraham. 2005. "Developing and Using Symbol Sense in Mathematics." For the Learning of Mathematics 25 (2): 42-47.

Aristotle, and C. D. C. Reeve. 2014. Nicomachean Ethics. Indianapolis: Hackett Publishing Co., Inc.

Berry, Robert Q. III. 2008. “Access to Upper-Level Mathematics: The Stories of Successful African American Middle School Boys.” Journal for Research in Mathematics Education 39 (5): 464-488.

Brighouse, Harry. 2006. On Education. London: Routledge. https://doi.org/10.4324/9780203390740.

Bruner, Jerome S. 1977. The Process of Education (2nd ed.). Cambridge, MA: Harvard University Press.

Burger, Edward B., and Michael P. Starbird. 2012. The Heart of Mathematics: An Invitation to Effective Thinking (4th ed). Hobokin, NJ: Wiley. 
Cohen, Patricia C. 2002. A Calculating People: The Spread of Numeracy in Early America (2nd ed.). New York: Routledge.

Cranfield, Corvell. 2012. "The Implementation of Mathematical Literacy as a New Subject in the South African Curriculum.” Learning and Doing Policy Analysis in Education 16: 207-232. https://doi.org/10.1007/978-94-6091-9336_8.

de Bassa Scheresberg, Carlo. 2013. "Financial Literacy and Financial Behavior Among Young Adults: Evidence and Implications.” Numeracy 6 (1): Article 5.

Dewey, John. 1920. Democracy and Education: An Introduction to the Philosophy of Education. New York: Macmillan.

Dowling, Paul. 1998. The Sociology of Mathematics Education: Mathematical Myths, Pedagogic Texts (1st ed.). Washington, DC: Falmer Press.

Eide, Eric, and Jeffrey Grogger. 1995. "Changes in College Skills and the Rise in the College Wage Premium.” Journal of Human Resources 30 (2): 280-310. https://doi.org/10.2307/146120.

Erickson, Anders W. 2016. "Rethinking the Numerate Citizen: Quantitative Literacy and Public Issues.” Numeracy 9 (2): Article 4.

Ernest, Paul. 2002. The Philosophy of Mathematics Education (1st ed.). Great Britain: Routledge Falmer.

Fagerlin, Angela, Peter Ubel, Dylan Smith, and Brian Zikmund-Fisher. 2007. "Making Numbers Matter: Present and Future Research in Risk Communication.” American Journal of Health Behavior 31: S47-56. https://doi.org/10.5993/AJHB.31.s1.7.

Ferkany, Matthew. 2012. "The Objectivity of Well-Being.” Pacific Philosophical Quarterly 93 (4): 472-492. https://doi.org/10.1111/j.14680114.2012.01435.x.

Gadanidis, George. 2012. "Why Can't I Be a Mathematician?” For the Learning of Mathematics 32 (2): 20-26.

Gibson, Richard. 1986. "Logic as a Core Curriculum Subject: Its Case as an Alternative to Mathematics.” Journal of Philosophy of Education 20 (1): 2137. https://doi.org/10.1111/j.1467-9752.1986.tb00107.x.

Hillyard, Cinnamon. 2012. "Comparative Study of the Numeracy Education and Writing Across the Curriculum Movements: Ideas for Future Growth.” Numeracy 5 (2): Article 2.

Hilton, Peter. 1984. "Current Trends in Mathematics and Future Trends in Mathematics Education.” For the Learning of Mathematics 4 (1): 2-8. Hughes-Hallett, Deborah. 2003. "The Role of Mathematics Courses in the Development of Quantitative Literacy.” In Quantitative Literacy: Why Numeracy Matters for Schools and Colleges, edited by L. A. Steen and B. L. 
Madison, 91-98. Princeton, NJ: National Council on Education and the Disciplines.

Jasper, John D., Chandrima Bhattacharya, Irwin P. Levin, Lance Jones, and

Elaine Bossard. 2013. "Numeracy as a Predictor of Adaptive Risky Decision Making.” Journal of Behavioral Decision Making 26 (2): 164-173. https://doi.org/10.1002/bdm.1748.

Johnson, David B., and Thomas A. Mowry. 2015. Mathematics: A Practical Odyssey. Boston, MA: Brooks Cole.

Karaali, Gizem, Edwim H. Villafane Hernandez, and Jeremy A. Taylor. "What's in a Name? A Critical Review of Definitions of Quantitative Literacy, Numeracy, and Quantitative Reasoning.” Numeracy 9 (1): Article 2. http://dx.doi.org/10.5038/1936-4660.9.1.2.

Kilpatrick, Jeremy, Jane Swafford, and Bradford Findell, eds. 2001. Adding It Up: Helping Children Learn Mathematics. Washington, D.C.: National Academy Press.

Labaree, David F. 1997. "Public Goods, Private Goods: The American Struggle over Educational Goals.” American Educational Research Journal 34 (1): 39-81. https://doi.org/10.3102/00028312034001039.

—. 2014. "Let's Measure What No One Teaches: PISA, NCLB, and the Shrinking Aims of Education.” Teachers College Record 116 (9): 1.

Lipkus, Issac M., and Ellen Peters. 2009. "Understanding the Role of Numeracy in Health: Proposed Theoretical Framework and Practical Insights.” Health Education \& Behavior 36 (6): 1065-1081. https://doi.org/10.1177/1090198109341533.

Levy, Frank, Richard J. Murnane, and John B. Willett. 1995. “The Growing Importance of Cognitive Skills in Wage Determination.” Review of Economics and Statistics 77 (2): 251-266. https://doi.org/10.2307/2109863.

Madison, Bernard L. 2003. “Articulation and Quantitative Literacy: A View from Inside Mathematics.” In Quantitative Literacy: Why Numeracy Matters for Schools and Colleges, edited by L. A. Steen and B. L. Madison, 153-164. Princeton, NJ: National Council on Education and the Disciplines.

—. 2015. "Quantitative Literacy and the Common Core State Standards in Mathematics.” Numeracy 8 (1): Article 11.

Mills, Charles W. 1959. The Sociological Imagination. New York: Oxford University Press.

Mumford, David. 2006. “Mathematics Belongs in Any Liberal Education.” Arts and Humanities in Higher Education 5 (1): 21-32. https://doi.org/10.1177/1474022206059995.

National Council of Teachers of Mathematics. 2000. Principles and Standards for School Mathematics. Reston, VA: Author. 
National Governors Association Center for Best Practices and Council of Chief State School Officers. 2010. Common Core State Standards for Mathematics. Washington, DC: Authors.

Nussbaum, Martha C., and Amartya Sen. 1999. The Quality of Life. New Delhi: Oxford University Press.

Nye, Pete, and Cinnamon Hillyard. 2013. "Personal Financial Behavior: The Influence of Quantitative Literacy and Material Values.” Numeracy 6 (1): Article 3.

Oakes, Jeannie. 1982. "The Reproduction of Inequity: The Content of Secondary School Tracking.” The Urban Review 14 (2): 107-120. https://doi.org/10.1007/BF02174647.

Pais, Alexandre. 2013. "Ethnomathematics and the Limits of Culture." For the Learning of Mathematics 33 (3): 2-6.

Postman, Neil. 1996. The End of Education: Redefining the Value of School. New York: Vintage.

Rice, Christopher M. 2013. "Defending the Objective List Theory of WellBeing.” Ratio: An International Journal of Analytic Philosophy 26 (2): 196211. https://doi.org/10.1111/rati.12007.

Rivera-Batiz, Francisco L. 1992. "Quantitative Literacy and the Likelihood of Employment Among Young Adults in the United States.” Journal of Human Resources 27 (2): 313-328. https://doi.org/10.2307/145737.

Rosen, Linda P., Lindsay Weil, and Claus V. Zastrow. 2003. "Quantitative Literacy in the Workplace: Making It a Reality.” In Quantitative Literacy: Why Numeracy Matters for Schools and Colleges, edited by L. A. Steen and B. L. Madison, 43-52. Princeton, NJ: National Council on Education and the Disciplines.

Rothman, Russell L., Ryan Housam, Hilary Weiss, Dianne Davis, Rebecca Gregory, Tebeb Gebretsadik, Ayumi Shintani, and Tom A. Elasy. 2006. "Patient Understanding of Food Labels: The Role of Literacy and Numeracy.” American Journal of Preventive Medicines 31 (5): 391-398. https://doi.org/10.1016/j.amepre.2006.07.025.

Schoenfeld, Alan H. 2004. “The Math Wars.” Educational Policy, 18 (1): 253286. https://doi.org/10.1177/0895904803260042.

- 2016. "Learning to Think Mathematically: Problem Solving, Metacognition, and Sense Making in Mathematics (Reprint).” Journal of Education 196 (2): 1-38.

Seligman, Martin E. P. 2011. Flourish: A Visionary New Understanding of Happiness and Well-Being (1st ed.). New York: Free Press.

Siegel, Harvey. 1988. Educating Reason: Rationality, Critical Thinking, and Education. New York: Routledge and Kegan Paul. 
Silva, Cynthia M., Robert P. Moses, Jacqueline Rivers, and Parker Johnson. 1990. "The Algebra Project: Making Middle School Mathematics Count." The Journal of Negro Education 59 (3): 375-391. https://doi.org/10.2307/2295571.

Stanic, George. 1986. "The Growing Crisis in Mathematics Education in the Early Twentieth Century.” Journal for Research in Mathematics Education 17 (3): 190-205. https://doi.org/10.2307/749301.

Steele, Benjamin, and S. Kiliç-Bahi. 2008. "Quantitative Literacy Across the Curriculum: A Case Study.” Numeracy 1 (2): 3. https://doi.org/10.5038/19364660.1.2.3.

Steen, Lynn A. 1997. Why Numbers Count: Quantitative Literacy for Tomorrow's America. New York: College Entrance Examination Board.

- (exec. ed). 2001. Mathematics and Democracy: The Case for Quantitative Literacy. The Woodrow Wilson National Fellowship Foundation, National Council on Education and the Disciplines. Accessed July 14, 2016. http://www.maa.org/ql/mathanddemocracy.html.

Tunstall, Samuel L. 2016. "Words Matter: Discourse and Numeracy.” Numeracy 9 (2): Article 5.

Whitehead, Alfred. 1929. The Aims of Education and Other Essays. New York, Macmillan.

Whitney, H. 1987. "Coming Alive in School Math and Beyond." Educational Studies in Mathematics 18 (3): 229-242. https://doi.org/10.1007/BF00386196.

Wilkins, Jesse L. M. 2010. "Modeling Quantitative Literacy.” Educational and Psychological Measurement 70 (2): 267-290. https://doi.org/10.1177/0013164409344506.

Williams, Julian. 2012. "Use and Exchange Value in Mathematics Education: Contemporary CHAT Meets Bourdieu's Sociology.” Educational Studies in Mathematics 80 (1): 57-72. https://doi.org/10.1007/s10649-011-9362-x.

Woodhouse, Howard. 2012. "Mathematics as Liberal Education: Whitehead and the Rhythm of Life.” Interchange 43 (1): 1-23. https://doi.org/10.1007/s10780-012-9169-4. 